\title{
Adding Flexibility and Hands-On Experiences while Minimizing Sequential Gaps in the ME Curriculum
}

\section{Dr. Matt Gordon P.E., University of Denver}

Dr. Matt Gordon is Professor and Chair of the Department of Mechanical \& Materials Engineering at the University of Denver. His research areas include numerical and experimental plasma physics, chemical and physical vapor deposition, electronic packaging, and bio-medical engineering. He has over 100 publications including 1 book chapter. Courses taught include undergraduate finite elements, thermodynamics, fluid dynamics, heat transfer, and engineering economics and ethics, and graduate finite elements, numerical methods, thermodynamics, statistical mechanics, plasma fundamentals and gas dynamics.

\section{Bradley S. Davidson, University of Denver}

Bradley Davidson is an Assistant Professor in Mechanical Engineering and director of the Human Dynamics Laboratory at the University of Denver. He holds a BS in civil engineering from Tennessee Tech, an MS in engineering mechanics from Virginia Tech, and a $\mathrm{PhD}$ in biomedical engineering from the Virginia Tech-Wake Forest School of Biomedical Engineering and Sciences. His research in musculoskeletal biomechanics emphasizes measurement of human movement and motor control, with applications in the lumbar spine stability, total knee arthroplasty, and Parkinson's Disease.

\section{Prof. Corinne Shirley Lengsfeld, University of Denver}

Dr. Lengsfeld is a Professor at the University of Denver. She received her bachelors, masters and Ph.D. degrees from the University of California at Irvine in 1992, 1993, and 1997 respectively. She specializes in interdisciplinary research in meso and micro-scale fluid systems. Her work has included investigation of biopharmaceutical delivery and processing, inhaled aerosol and deposition and optimization of complex fluid systems. She has developed an automated CFD-based optimization process that is currently aiding in the development of gas-turbine blades, solid state lasers, the next generation aerosols for reliable drug deposition to the lung, improved shipping and vial filling practices for biopharmaceuticals. Most recently her research group has moved to fluid-solid modeling to incorporate structural influences in the optimization of the fluid systems.

Her work has been cited 300 times by more than 242 articles resulting in a web of science H-index of 10 and an average impact factor of 2.57. During her 13 years at the University of Denver she has received $\$ 1.39$ Million in external research funding and $\sim 2.62$ Million in external educational funding from agencies like NSF, DHHS, DOL, DOD, State of Colorado, Keck Foundation among others.

Dr. Lengsfeld serves as editorial in chief for the journal Atomization and Sprays. 


\title{
Adding Flexibility and Hands-On Experiences while Minimizing Sequential Gaps in the ME Curriculum
}

\begin{abstract}
The Department of Mechanical and Materials Engineering at the University of Denver recently undertook a strategic planning process to identify critical changes to the program needed to address how the modern BSME degree is applied or will be utilized in the future. Three initiatives were implemented as a result of this process: (1) increase the number of hands-on experiences to differentiate from online curricula, (2) add flexibility in general and in technical electives to allow students to tailor their educational experiences to their long term goals, and (3) minimize gaps between courses intended to build on each other. Hands-on experiences now exist in all but one quarter of our four-year curriculum. The experiences incorporate open ended design problems as well as thoughtfully constructed laboratory experiences. Flexibility has been added by allowing students to select three to four courses from pre-approved math and science courses, by opening up the timing of these courses as well as general educational requirements within the four year curriculum, by doubling the number of mechanical engineering technical electives available, and by allowing students to take technical electives from any of our three engineering programs (Mechanical, Electrical, and Computer Engineering). Moreover in collaboration with the University of Denver's Law School, our students can now satisfy a technical elective requirement by taking the Law School's Introduction to Intellectual Property course. Finally the faculty worked to identify all follow-on courses and rearranged the curriculum to minimize the gaps between one class to the next.
\end{abstract}

\section{Introduction}

The Daniel F. Ritchie School of Engineering and Computer Science rigorously evaluated its academic and research programs, assessed program strengths and weaknesses, and identified strategic opportunities. All faculty and some staff participated in the candid evaluation of undergraduate, graduate, faculty/staff, and resource programs that contributed to the schools missions in recruitment and retention, teaching and learning, research, and career development. The resulting plan was rooted in the recognition that we live in a time of international transition and opportunity where the traditional model of the University is challenged, and even the return on investment of higher education is questioned.

The Mechanical and Materials Engineering (MME) Department's strategic planning process included all associated faculty and staff. Consistent with the department vision over the past decade, MME wants to implement initiatives that provide clear reasons for students and parents to select the University of Denver's (DU) MME department for the educational cost today and tomorrow. Among the initiatives that resulted were: (1) increase the number of hands-on experiences to differentiate from online curricula, (2) add flexibility in general and in technical electives to allow students to tailor their educational experiences to their long term goals, and (3) minimize gaps between courses intended to build on each other. 
Results and Discussion

Increased hands-on experiences

In the face of the growing movement toward online courses, this initiative will uniquely prioritize experiential hands-on learning. Our students identify with innovation and entrepreneurship, paralleling recent success in technology and design firms (Apple, Google, Ideo). New Growth Theory ${ }^{1}$ demonstrates that economic growth does not arise just from adding more labor to more capital but from new and better technological ideas. Approximately one out of every three of our engineering students earns a dual degree (BSME and MBA) in five years. More often than not these students select this path because they see the opportunity to enhance economic growth through technology applications. In the Management Department of DU's Daniels College of Business a new Entrepreneur program has been initiated to help students of all disciplines study innovation models. Within MME we are seeking specifically to enhance the concept-to-product realization innovation pipeline. The experiences of taking an idea from concept to product and participating in a unique multidisciplinary environment will prepare students well for employment after graduation. These types of experiences are essential for transforming knowledgeable students into "knowledge-able" workers and an innovative curriculum is highlighted as an essential role of higher education in the future. ${ }^{2}$

The current US Administration proposes to move manufacturing back to our shores. Many schools are limiting legal risk by restricting student access to these manufacturing facilities such as machine shops. Perhaps because we are a small program (roughly 200 total engineering students), we are able to keep our machine shop open to all students once properly trained in safety and proper operations. Our recent initiative enhances our current machining capabilities, develops the manufacturing capacity of the MME facilities, and incorporates a hands-on experience of both undergraduate and graduate students.

Our changes impact students throughout the curriculum. First year students work in teams of three to design a small projectile launching device equivalent to a child's toy. Teams work through innovation and design processes of problem identification, goal setting, research, prototyping, evaluation, and reflection. Labs during the quarter provide students skills in solid modeling and projectile motion and design documentation, but the final project requires them to synthesize these lessons into a single product. Students design the device virtually in SolidWorks, evaluating assembly issues of contact interference and can conduct some rudimentary performance optimization. The device size is limited to a particular volume of 3-D printing material and by the maximum and minimum number of components. All teams must complete a formal design review process before submitting the designs for 3-D printing. While waiting for parts to be manufactured, teams document the design and analysis activities. Parts are returned to students after one week for assembly and testing. What we find at the freshman level is that teams that commit themselves to the computer-aided-engineering evaluation process are more successful than those that do not. We also find that teams that conduct research into materials beyond those provided in class typically are more innovative and successful in performance testing. 
Our other changes innovate by adding dedicated laboratory sections in Statics and Dynamics, courses that are often taught as only theoretical in many engineering programs. A primary goal in each topic covered was to provide an opportunity for teams of two to set up the experiment, collect and analyze their own data, and write a 2-page formatted report on the results. This strategy moves beyond classroom demonstration and allows students to develop intuition on physical systems in addition to what can be gained using the textbook. The Static laboratories have been delivered two times and covered the following topics: 2D Equilibrium, 2D Moments, Centroids and 3D Equilibrium, Truss Design, and Internal Forces in a Beam. The format of delivery is similar in the Dynamics Laboratories described next; however, we also focus on forward simulations of equations of motion using Matlab to explore this fundamental concept.

The Dynamics Laboratories have been delivered once and covered the following topics: Kinematics of a Loop-the-Loop, Solving Equations of Motion, Friction on a Single Particle, Kinematics of a Four-Bar Mechanism, and Quantifying Rotational Inertia. Despite the rudimentary nature of these first attempts, feedback from the students has been very positive. We will continue to develop these with the intention of disseminating them for use in other ME programs that desire to take this approach in their introductory mechanics courses.

As a result, DU MME students are exposed to some form of hands-on learning in all but one of their twelve quarters, and in all six quarters during their first two years. Because we are a relatively small program (again, about 200 total engineering students), we are able to increase the amount of hands-on activities with our current resources. We are fortunate to have a new engineering building set to open in 2016 with better and larger facilities to allow us to continue this plan.

\section{Added flexibility}

The implementation plan included adding flexibility to the curriculum to enhance retention and provide opportunities for students to consider medical school, law school, business school, etc. while pursuing a major in engineering. Often engineering is considered a major providing no opportunity to explore other options. Certainly, ABET accreditation limits such flexibility, but we found there were sufficient options while still meeting ABET requirements. One of the core ABET requirements ${ }^{3}$ is a minimum number of math and/or science hours (one year defined as 32 semester or 48 quarter hours). However, rather than specify which math and science courses should be taken, our program was opened up to allow students to choose among a list of math and science courses. In this way, each student could tailor their choices to best fit their career interests and/or to explore other options such as medical school.

Specifically, we still require one full year of calculus plus one quarter of differential equations and one quarter of multi-variable calculus. We also require one full year of calculus-based physics and one quarter of chemistry. However, that is still 10 quarter hours short of fulfilling ABET requirements. For these last 10 quarter hours, students are free to choose from biology for biology majors, chemistry beyond the already required general chemistry (organic, physical, etc. designed for chemistry majors), physics beyond the required first year (modern physics, optics, etc. designed for physics majors), and/or math (linear algebra, probability, etc. designed for math majors). For student particularly interested in the sciences (pre-med students for one example), 
we allow them to take another 4 quarter hours above the minimum 10 while still counting all credits towards their degree. This additional 4 quarter hours replaces one technical elective described next. Initial results indicate that the most popular math/science option is physics with math, particularly linear algebra, the next most popular choice. Chemistry beyond general chemistry appears to be least popular choice except for about the 3 students planning to attend medical school.

In addition to flexibility in math and science, we opened our program up such that students could take their technical electives in any of our three engineering majors (mechanical, electrical, and computer). By opening up these elective to other departments, we were able to increase the number offered without impacting our department's course load. In the past two years, we were allowed to hire a full-time lecturer which allowed us to offer additional MME technical electives. These two actions combined led to the doubling of available electives. Again, this allows students to tailor their program to match their interests among these coupled majors. Finally, we collaborated with our Law School to allow our students to take an Introduction to Intellectual Property through the Law School with second and third year law students. This option has been in place for two years and after this year, a total of ten junior and senior engineering students (representing about $15 \%$ of each class) will have taken the course. Responses from the first five taking the course last year were overwhelmingly positive with two of the five now considering Law School in general and Patent Law in particular.

\section{Minimization of course sequencing gaps}

Especially on the quarter system, courses are often broken up over different academic periods. While mechanical engineering semester programs typically offer one semester of fluids and one semester of heat transfer, our quarter program also offers 15 teaching weeks of each topic, but spread out in three 10-week (quarter) courses. Before our curriculum changes, we offered this sequence starting in the winter quarter such that there was a summer break between the last two courses. As part of our curriculum changes, we moved this sequence to begin in the fall quarter to minimize the course sequencing gaps.

Additionally, another advantage of having this fluids/heat transfer sequence finish in the spring quarter is that students can now more easily travel overseas in the fall quarter of the senior year when the third part of the sequence used to be taken. We strongly believe that so-called out-ofclass experiences are an important element to our curricular design. All of our students are encouraged to engage in undergraduate research, to study abroad, and to pursue co-ops and/or internships. In fact, we are moving towards making such an out-of-class experience required prior to graduation.

We also altered the curriculum to provide a more comprehensive experience in Systems Engineering to minimize another type of sequencing gap. Mechanical Engineering is built on a series of disparate subjects (solids, thermodynamics, fluids mechanics, and Newtonian dynamics) that appear unrelated until a student experiences, for example, the balance laws governing mass, momentum, and energy in a graduate course in Continuum Mechanics. In our curriculum, students now encounter these through sequences spanning the sophomore and junior years as follows: Solids (4 courses), Thermodynamics (2 courses), Fluid Mechanics (3 courses), 
and Newtonian Dynamics (2 courses). In addition, we added a course in System Dynamics to the 3rd year that unifies these mechanical disciplines, along with DC Circuits, and focuses on system modeling, energy transfer through bond graphs, and control of linear systems. These changes essentially eliminate another course gap and position the students to effectively move beyond standard textbook problems, applying their engineering knowledge and skills to innovate on multidisciplinary projects.

Overall, our objectives are to increase the ratio of the number of students depositing to the program to the number of students accepted to the program, to increase the persistent rate of students, and to increase the depth of learning as measured by the Fundamentals of Engineering Exam. An early measure of our success can be observed through the selection of discipline by our students at the end of a two year common engineering curriculum. The freshmen who entered our program in the fall of 2011 represent the first wave of students to enter this new format. Roughly $85 \%$ of this population selected a BSME over BSEE and BSCompE. Prior to 2011, roughly $50 \%$ of the students chose the BSME program. Additionally, during the past two years, our FE pass rates exceeded $90 \%$. These early findings suggest that it is possible for ME curricula to accommodate the direction and desires of engineering students while exceeding ABET requirements.

As a brief aside on the FE since the format of the exam was just changed, we note that we anticipate little impact to our program. Our program is highly sequenced with few courses offered more than once a year. Thus, our students all take the FE exam towards the end of their senior year - in the spring. Before, this meant they would all take the exam on the same day in April. Now, we anticipate that students will take the exam in April or May depending on which offering best suits their schedules.

\section{Conclusions}

We recognize that our program must demonstrate the value for the cost. Because many aspects of university education do not translate directly to dollars and cents, the learning experiences we provide must be lasting and of substantive value inside and outside the classroom. Therefore, our efforts to increase the opportunities for hands-on experiences, adding flexibility to the engineering curriculum, and minimizing gaps between sequenced courses represent actions with low monetary cost that will directly affect student experience. Successful implementation will enhance the educational value offered and provide quantitative metrics that students and parents can use to assess their return on investment. Initial results from our implementation have been very encouraging.

\section{References}

1. Romer, P.M., Endogenous Technological Change, Journal of Political Economy, Vol. 98, No. 5, 1990, pp. S71-S102

2. U.S. Department of Education, A Test of Leadership: Charting the Future of U.S. Higher Education, Washington, D.C., 2006.

3. http://www.abet.org/eac-criteria-2014-2015/ 